\title{
LC-MS/MS CHARACTERIZATION OF FORCED DEGRADATION PRODUCTS OF TUCATINIB, A NOVEL TYROSINE KINASE INHIBITOR: DEVELOPMENT AND VALIDATION OF RP-HPLC METHOD
}

\author{
S. K. REEHANA ${ }^{1}{ }^{*}$, K. SUJANA ${ }^{1}$

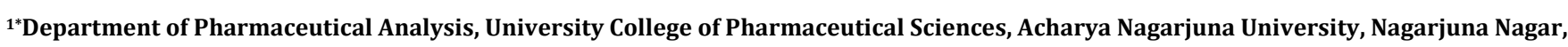 \\ Guntur 522510, Andhra Pradesh, India \\ Email: reehana28@gmail.com
}

Received: 28 Sep 2021, Revised and Accepted: 09 Nov 2021

\section{ABSTRACT}

Objective: The current study focused on the development, validation, and characterization of forced degradation products using LC-MS/MS.

Methods: A simple, selective, validated and well-defined isocratic HPLC methodology for the quantitative determination of Tucatinib at a wavelength of $239 \mathrm{~nm}$. An isocratic elution of samples was performed on an Inertsil ODS (250x4.6 mm, 5m) column with a mobile phase of 70:30v/v Acetonitrile and formic acid (0.1\%) delivered at a flow rate of $1.0 \mathrm{ml} / \mathrm{min}$. MS/MS was used to characterize degradation products formed in the forced degradation study. The validation and characterization of forced degradation products were performed in accordance with ICH guidelines.

Results: Over the concentration range of $5-100 \mu \mathrm{g} / \mathrm{ml}$, a good linear response was obtained. Tucatinib's LOD and LOQ were determined to be 0.05 and 0.5 , respectively. According to standard guidelines, the method was quantitatively evaluated in terms of system suitability, linearity, precision, accuracy, and robustness, and the results were found to be within acceptable limits. The drug was degraded under acidic, alkaline, and reduction conditions in forced degradation studies.

Conclusion: The method was found to be applicable for routine tucatinib analysis. Because no LC-MS/MS method for estimating tucatinib and its degradation products has been reported in the literature. There is a need to develop a method for studying the entire tucatinib degradation pathway.

Keywords: LC-MS/MS, Tucatinib, Method development, Validation, Degradation pathways

(C) 2022 The Authors. Published by Innovare Academic Sciences Pvt Ltd. This is an open-access article under the CC BY license (https://creativecommons.org/licenses/by/4.0/) DOI: https://dx.doi.org/10.22159/ijap.2022v14i1.43252. Journal homepage: https://innovareacademics.in/journals/index.php/ijap

\section{INTRODUCTION}

Tucatinib belongs to a class of drugs known as kinase inhibitors [1, 2]. Tucatinib's chemical name is N6-(4,4-dimethyl-4,5-dihydro-1,3oxazol-2-yl)-N4-(3-methyl-4-[1,2,4] triazolo[1,5-a]pyridin-7-

yloxyphenyl)quinazoline-4,6-diamine. Tucatinib's molecular formula and molecular weight are $\mathrm{C}_{26} \mathrm{H}_{24} \mathrm{~N}_{8} \mathrm{O}_{2}$ and $480.5212 \mu \mathrm{g} / \mathrm{mol}$, respectively. Tucatinib, sold under the brand name Tukysa, is a small molecule inhibitor of HER2 for the treatment of HER2-positive breast cancer $[3,4]$. It works by preventing the abnormal protein from signalling cancer cells $[5,6]$ to multiply. This aids in the prevention or slowing of the spread of cancer cells. Tucatinib, in combination with trastuzumab and capecitabine, was approved by the FDA on April17, 2020 for the treatment of patients with advanced unresectable or metastatic HER2-positive breast cancer.

Tucatinib inhibits HER2 and HER3 phosphorylation $[7,8]$ in vitro, resulting in inhibition of downstream MAPK $[9,10]$ and AKT $[11,12]$ signalling and cell proliferation, and has anti-tumor activity in HER2 expressing tumour cells. Tukysa is the brand name for tucatinib. Array BioPharma developed it. Patients with human epidermal growth factor receptor 2 (HER2)-positive metastatic breast cancer who progress after multiple HER2-targeted agents have few treatment options. Common side effects are diarrhea, palmarplantar erythrodysesthesia [13, 14] (burning or tingling discomfort in the hands and feet), nausea, fatigue, hepatotoxicity [15] (liver damage), vomiting, stomatitis [16] (inflammation of the mouth and lips), decreased appetite [17], abdominal pain [18], headache, anemia and rash. Pregnant or breastfeeding women should not take Tucatinib because it may cause harm to a developing fetus or newborn baby.

There are only a few methods available for tucatinib. There are preclinical studies available, but no analytical methods are reported. The purpose of this research is to create, validate, and characterize forced degradation products using LC-MS/MS.

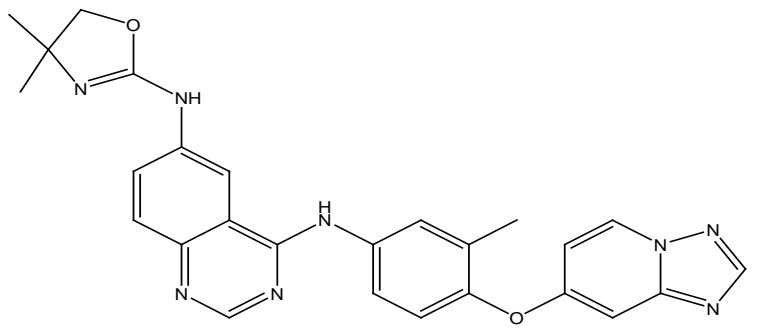

Fig. 1: Chemical structure of tucatinib

\section{MATERIALS AND METHODS}

\section{Chemicals and reagents}

Shree Icon Lab provided the pure Tucatinib standard (Vijayawada, India). Finar Chemicals supplied HPLC-grade acetonitrile and formic acid (Ahmedabad, India). Filtration through a Millipore MilliQ plus system produced HPLC grade water (Millipore, USA). Merck supplied analytical grade reagents of sodium hydroxide, hydrochloric acid, 30\% hydrogen peroxide, and sodium bisulphate (Mumbai, India).

\section{Instrumentation}

HPLC

Waters alliance model e2695 liquid chromatography instrument, Waters (2998) Photodiode array Detector, Waters (2700) Auto sample injector, Solvent degasser, Quaternary pump, Temperaturecontrolled compartment. Using a sonicator, all of the solutions were sonicated for effective mixing and degassing (Unichrome associates 701). Weighing is done with an analytical balance (Denver). A hot air oven was used to conduct a thermal degradation study (KEMI). 


\section{LC-MS/MS}

An HPLC system (waters alliance e2695 model) connected with mass spectrometer QTRAP 5500 triple quadrupole instrument (sciex) was used [19-21].

\section{Method optimization}

Several parameters, including mobile phase, stationary phase, flow rate, and detector wavelength, were considered when developing and optimising the chromatographic separation conditions. Isocratic elution with mobile phase $70: 30 \mathrm{v} / \mathrm{v}$ Acetonitrile and formic acid $(0.1$ percent) pumped from a solvent reservoir at a flow rate of $1.0 \mathrm{ml} / \mathrm{min}$ to the analytical column of the Inertsil ODS (250x4.6 mm,5m) using column back pressure of $1570-1620$ at the maximum detector wavelength of $239 \mathrm{~nm}$ was used to obtain a chromatographic separation. Detector performance was evaluated using Empower-2 software to determine the height peak area and other device suitability parameters. The injection volume was set at $10 \mathrm{l}$, the ambient column temperature was maintained throughout the analysis.

\section{Validation procedure}

The developed method for estimation of Tucatinib was verified according to ICH regulations for system suitability, specificity, linearity, accuracy, precision, ruggedness, robustness, limit of detection, and limit of quantification [22-25].

\section{Preparation of mobile phase}

Acetonitrile and formic acid were mixed in a $70: 30 \mathrm{v} / \mathrm{v}$ ratio then filtered through $0.45 \mu \mathrm{m}$ filter paper and sonicated to remove any gas.

\section{Chromatographic conditions}

Tucatinib was separated chromatographically in an Inertsil ODS (250x4.6 mm, 5m) column. The mobile phase was composed of acetonitrile and formic acid $(70: 30 \mathrm{v} / \mathrm{v})$ and was pumped at room temperature at a flow rate of $1 \mathrm{ml} / \mathrm{min}$ with a UV detection wavelength of $239 \mathrm{~nm}$ and filtered through a $0.45 \mathrm{~m}$ nylon membrane filter under vacuum filtration. The injection volume was ten $\mu$ litres. Tucatinib had a retention time of $3.734 \mathrm{~min}$, while the run lasted $6 \mathrm{~min}$.

\section{Diluents}

Mobile phase was used as diluents.

\section{Preparation of standard solution}

Tucatinib standard stock solution was prepared by dissolving 100 $\mathrm{mg}$ of Tucatinib in $100 \mathrm{ml}$ of diluents in a $100 \mathrm{ml}$ clean and dry volumetric flask, and the standard solution was filtered through a $0.45 \mathrm{~m}$ membrane filter and degassed with a sonicator to obtain a concentration of $1000 \mathrm{~g} / \mathrm{ml}$ of Tucatinib.

\section{Selection of wavelength}

A UV-Visible spectrophotometer was used to scan the maximum absorption wavelength of $50 \mathrm{~g} / \mathrm{ml}$ Tucatinib against a blank mobile phase in the wavelength range of $200-400 \mathrm{~nm}$. As shown in fig. 2, the maximum wavelength was discovered to be $239 \mathrm{~nm}$.

\section{Forced degradation of tucatinib}

\section{Acid degradation}

Tucatinib solution was treated with $1 \mathrm{~N} \mathrm{HCl}$, heated for $6 \mathrm{~h}$, and refluxed for $5 \mathrm{~h}$ before adding $1 \mathrm{ml}$ of $1 \mathrm{~N} \mathrm{NaOH}$ and diluting volume with diluents. Inject the solution into the HPLC system several times over the course of $6 \mathrm{~h}, 12 \mathrm{~h}, 18 \mathrm{~h}$, and $24 \mathrm{~h}$.

\section{Alkali degradation}

Tucatinib solution was treated with $1 \mathrm{~N} \mathrm{NaOH}$ for alkali degradation, heated for $6 \mathrm{~h}$, and refluxed for $5 \mathrm{~h}$ before adding $1 \mathrm{ml}$ of $1 \mathrm{~N} \mathrm{HCl}$ and diluting volume with diluents. Inject the solution into the HPLC system several times over the course of $6 \mathrm{~h}, 12 \mathrm{~h}, 18 \mathrm{~h}$, and $24 \mathrm{~h}$.

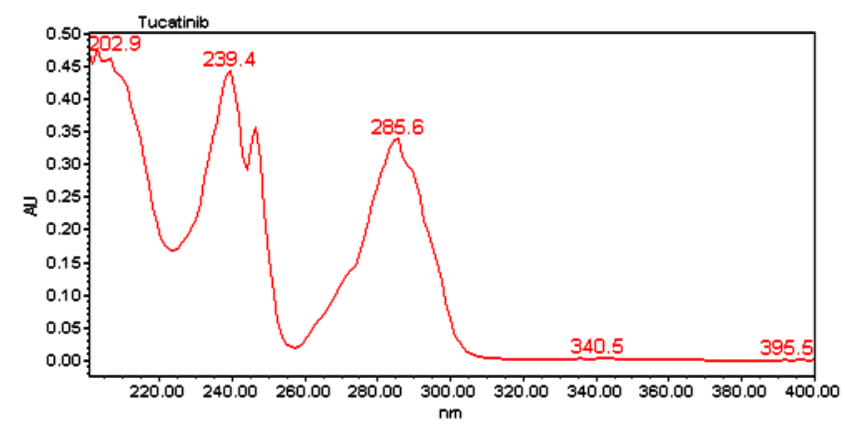

Fig. 2: PDA spectrum of tucatinib

\section{Peroxide degradation}

Tucatinib solution was treated with $30 \% \mathrm{H} 2 \mathrm{O} 2$ and refluxed for $5 \mathrm{~h}$, then heated for $3 \mathrm{~h}$ before cooling to room temperature and diluting with diluents. Inject the solution into the HPLC system several times over the course of $6 \mathrm{~h}, 12 \mathrm{~h}, 18 \mathrm{~h}$, and $24 \mathrm{~h}$.

\section{Reduction degradation}

Tucatinib solution was treated with $30 \%$ sodium bi sulphate solution, refluxed for $5 \mathrm{~h}$, heated to $3 \mathrm{~h}$, cooled to room temperature, and then diluted volume with diluent. Inject the solution into the HPLC system several times over the course of $6 \mathrm{~h}, 12 \mathrm{~h}, 18 \mathrm{~h}$, and $24 \mathrm{~h}$.

\section{Hydrolysis degradation}

Tucatinib solution was treated with $\mathrm{H} 2 \mathrm{O}$ and refluxed for $30 \mathrm{~min}$ before being heated for $3 \mathrm{~h}$, cooled to room temperature, and diluted volume with diluent. Inject the solution into the HPLC system several times over the course of $6 \mathrm{~h}, 12 \mathrm{~h}, 18 \mathrm{~h}$, and $24 \mathrm{~h}$.

\section{Thermal degradation}

$100 \mathrm{mg}$ of sample was exposed at $105^{\circ} \mathrm{C}$ for $6 \mathrm{~h}$ before being analysed. A sample of $62 \mathrm{mg}$ was transferred to a $100 \mathrm{ml}$ volumetric flask. Add $70 \mathrm{ml}$ of diluent, sonicate to dissolve, and dilute to volume with a diluent before mixing. Dilute $5 \mathrm{ml}$ to $50 \mathrm{ml}$ more with diluent. Inject the solution into the HPLC system several times over the course of $6 \mathrm{~h}, 12 \mathrm{~h}, 18 \mathrm{~h}$, and $24 \mathrm{~h}$.

\section{Photolytic degradation}

$100 \mathrm{mg}$ of sample was exposed at UV light for $6 \mathrm{~h}$ before being analysed. A sample of $62 \mathrm{mg}$ was transferred to a $100 \mathrm{ml}$ volumetric flask. Add $70 \mathrm{ml}$ of diluent, sonicate to dissolve, and dilute to volume with a diluent before mixing. Dilute $5 \mathrm{ml}$ to $50 \mathrm{ml}$ more with diluent. Inject the solution into the HPLC system several times over the course of $6 \mathrm{~h}, 12 \mathrm{~h}, 18 \mathrm{~h}$, and $24 \mathrm{~h}$.

\section{RESULTS AND DISCUSSION}

\section{Method development and optimization}

Initially, the RP-HPLC system was optimized using an Inertsil ODS $(250 \times 4.6 \mathrm{~mm}, 5 \mathrm{~m})$ column. To satisfy the system suitability parameters, a mixture of acetonitrile and formic acid $(70: 30 \mathrm{v} / \mathrm{v})$ as the mobile phase (Flow rate $1.0 \mathrm{ml} / \mathrm{min}$ ) was found to be more appropriate. Table 1 summarizes the optimized chromatographic conditions. At $3.734 \mathrm{~min}$, Tucatinib eluted as a sharp peak fig. 3 . 
Table 1: Optimized chromatographic conditions

\begin{tabular}{lll}
\hline LC conditions & & \\
\hline Stationary phase & $:$ & Inertsil ODS $(250 \times 4.6 \mathrm{~mm}, 5 \mu \mathrm{m})$ \\
Mobile Phase & $:$ & Acetonitrile and $0.1 \%$ formic acid $(70: 30)$ \\
Elution mode & $:$ & $1.0 \mathrm{ml} / \mathrm{min}$, \\
Flow rate & $:$ & $10 \mu \mathrm{l}$ using Rheodyne $7725 \mathrm{i}$ injector \\
Sample volume & $:$ & Ambient \\
Oven Temperature & & \\
MS conditions & $:$ & ESI \\
Interface & $:$ & MRM \\
Operation mode & $:$ & 4 KV \\
Polarity & $:$ & $170 \mathrm{~V}$ \\
Capillary voltage & $:$ & $65 \mathrm{~V}$ \\
Fragmentor voltage & $:$ & $40 \mathrm{psig}$ \\
Skimmer voltage & $:$ & $10 \mathrm{~L} / \mathrm{min}$ \\
Nebulizer Gas flow & $:$ & $325 \% \mathrm{C}$ \\
Drying gas & $:$ & $\mathrm{m} / \mathrm{z} 0-800$ \\
Gasoline temperature & $:$ & $\mathrm{ABSCIEX}$ \\
Detection & $:$ & \\
Data station & & \\
\hline
\end{tabular}

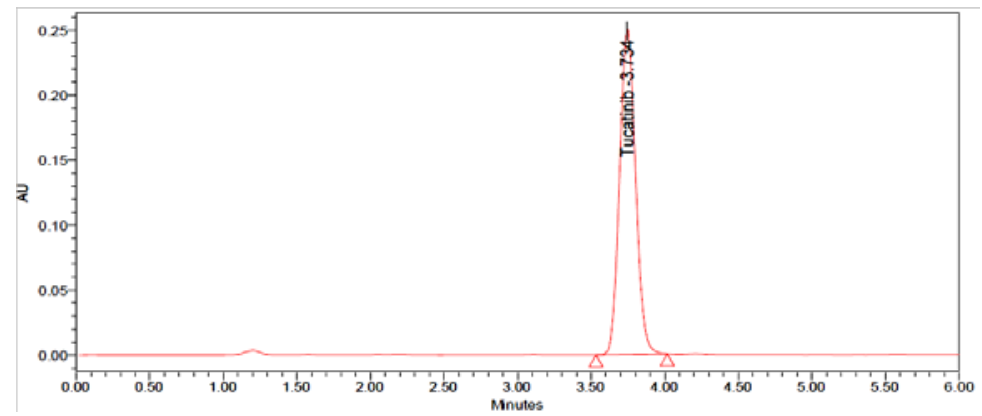

Fig. 3: Chromatogram of standard

\section{Method validation}

The proposed method was validated using the ICH guidelines [26] for system suitability (table 2), linearity (table 3), precision (table 4), accuracy (table 5), and robustness (table 6). The calibration curve was created by plotting tucatinib concentrations on the X-axis and the corresponding mean peak area values on the $\mathrm{Y}$-axis. Tucatinib follows Beer-law Lambert's at concentrations ranging from 5 to $100 \mu \mathrm{g} / \mathrm{ml}$, with the linear regression equation $y=35087 x+2540.4$ (correlation coefficient 0.999 fig. 4). The LOD and LOQ values are discovered to be
0.05 and 0.5 , respectively. Using three different concentrations of tucatinib, the percentage relative standard deviation (RSD) was found to be 1.01 and 0.83 , respectively ( 2.0 percent), demonstrating that the method is precise. The method's accuracy [27] was demonstrated using the standard addition method, and the recovery values were calculated. The percentage RSD was found to be $0.5(2.0 \%)$, with a recovery rate of 98.4-101.3 percent. In the robustness study [28], the percentage RSD was found to be $0.2-1.21$ ( 2.0 percent). The suitability of the system [29] and the stability of the solution was assessed, and the percentage RSD was $2 \%$. The results are shown in table 2.

Table 2: Results of system suitability

\begin{tabular}{lllll}
\hline System suitability parameter & Acceptance criteria & Tucatinib & & Std Dev \\
\cline { 3 - 5 } & & Mean & 30.651 & \% RSD \\
\hline USP Plate Count & NLT 2000 & 5594 & 0.55 \\
USP Tailing & NMT 2.0 & 1.10 & 0.015 & 1.34 \\
USP Resolution & NLT 2.0 & - & - & - \\
Retention time & NLT 2.0 & 3.735 & 0.003 & 0.09 \\
\hline
\end{tabular}

mean $\pm S D(n=6)$

Table 3: Results of linearity

\begin{tabular}{lll}
\hline S. No. & Conc $(\boldsymbol{\mu g} / \mathbf{m l})$ & Tucatinib area count \\
\hline 1 & 5.00 & 184880 \\
2 & 12.50 & 459113 \\
3 & 25.00 & 896209 \\
4 & 37.50 & 1206347 \\
5 & 50.00 & 1834505 \\
6 & 62.50 & 2178517 \\
7 & 75.00 & 2655617 \\
8 & 100.00 & 3502114 \\
Correl coef & & 0.99912 \\
Slope & & 35086.91 \\
intercept & & 2540.47 \\
\hline
\end{tabular}




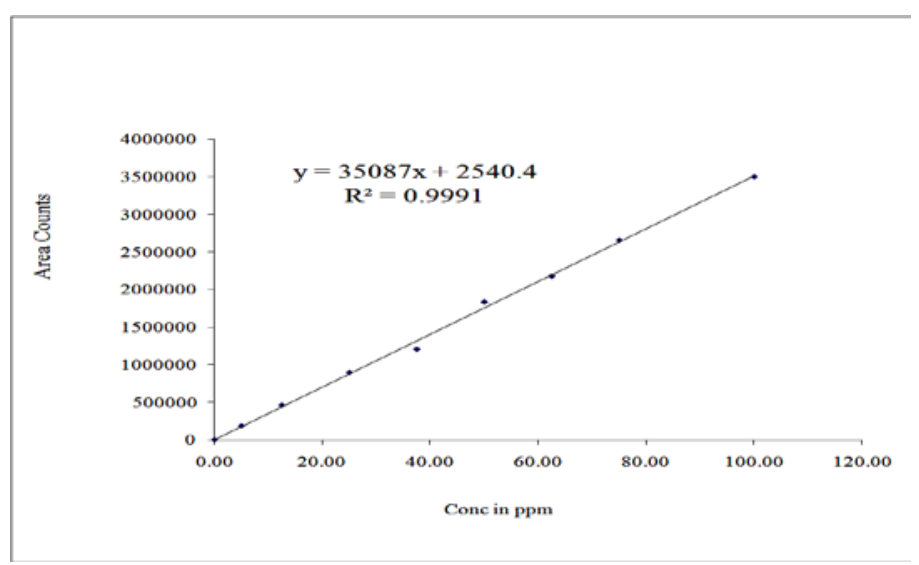

Fig. 4: Calibration curve for tucatinib at $239 \mathrm{~nm}$

Table 4: Results of method precision and Intermediate precision

\begin{tabular}{|c|c|c|c|c|c|c|}
\hline \multicolumn{7}{|c|}{ Tucatinib } \\
\hline \multirow[t]{2}{*}{ S. No. } & \multicolumn{3}{|c|}{ Method precision $^{\mathrm{a}}$} & \multicolumn{3}{|c|}{ Intermediate precision $^{b}$} \\
\hline & Conc. $(\mu \mathrm{g} / \mathrm{ml})$ & Area counts & \% assay as is & Conc. $(\mu \mathrm{g} / \mathrm{ml})$ & Area counts & \% assay as is \\
\hline 1 & 50 & 1870847 & 98.9 & 50 & 1900654 & 100.5 \\
\hline 2 & & 1897995 & 100.4 & & 1891351 & 100.0 \\
\hline 3 & & 1913999 & 101.2 & & 1863262 & 98.5 \\
\hline 4 & & 1907151 & 100.8 & & 1916471 & 101.4 \\
\hline 5 & & 1883482 & 99.6 & & 1875031 & 99.2 \\
\hline 6 & & 1896710 & 100.3 & & 1887356 & 99.8 \\
\hline \% RSD & 0.83 & & & 1.01 & & \\
\hline mean & 100.2 & & & 99.9 & & \\
\hline SD & 0.832 & & & 1.008 & & \\
\hline
\end{tabular}

a, b-Mean+SD $(n=6)$

Table 5: Results of accuracy

\begin{tabular}{|c|c|c|c|c|}
\hline S. No. & \% Level & Tucatinib \% recovery & Mean \% recovery & Std dev \\
\hline 1 & 50 & $\begin{array}{l}99.0 \\
100.1 \\
101.3\end{array}$ & 100.1 & 1.18 \\
\hline 2 & 100 & $\begin{array}{l}100.9 \\
100.0 \\
98.4\end{array}$ & 99.7 & 1.28 \\
\hline 3 & 150 & $\begin{array}{l}100.7 \\
100.2 \\
101.3\end{array}$ & 100.7 & 0.55 \\
\hline
\end{tabular}

Mean+SD $(n=3)$

Table 6: Results of robustness

\begin{tabular}{ll}
\hline Parameter name & \% RSD tucatinib \\
\hline Flow minus $(0.8 \mathrm{ml} / \mathrm{min})$ & 0.20 \\
Flow plus $(1.2 \mathrm{ml} / \mathrm{min})$ & 0.70 \\
Organic minus $(63: 37)$ & 0.61 \\
Organic plus $(77: 23)$ & 1.21 \\
\hline
\end{tabular}

RSD-Relative standard deviation; All the values are presented as mean $\pm S D(n=3)$

\section{Degradation studies}

Tucatinib was subjected to a variety of stress conditions [30], including acidic, oxidative, and alkaline hydrolysis. Tucatinib was eluted at $3.734 \mathrm{~min}$ in acidic hydrolysis. Tucatinib was eluted at 3.638 min with some degradants observed at 1.503 and 3.351 while performing acidic hydrolysis, with approximately 26.7 percent degradation observed. Tucatinib was eluted at 3.619 min during alkaline hydrolysis, with the other degradant observed at $1.336 \mathrm{~min}$ (drug degradation 24.7 percent). Tucatinib was eluted at $3.606 \mathrm{~min}$ during reduction, with degradant observed at $1.165 \mathrm{~min}$ and 21.6 percent degraded results are shown in table 7. The tucatinib peak was well separated among the degradants [31, 32] in all of the degradation studies, indicating that the method is selective and specific. Fig. 5 depicts typical chromatograms obtained during a stress degradation study of tucatinib. 
Table 7: Forced degradation results for tucatinib

\begin{tabular}{llll}
\hline Results: \% degradation results at $\mathbf{2 4} \mathbf{~ h}$ & Tucatinib & \\
\cline { 2 - 4 } & ${ }^{*}$ Mean area & ${ }^{*}$ \% Assay & \\
\hline Control & 1883286 & 99.6 & 0.4 \\
Acid & 1378506 & 73.3 & 26.7 \\
Base & 1424105 & 75.3 & 24.7 \\
Peroxide & 1466598 & 77.6 & 22.4 \\
Reduction & 1482593 & 78.4 & 21.6 \\
Thermal & 1489856 & 78.8 & 21.2 \\
Photolytic & 1492687 & 78.9 & 21.1 \\
Hydrolysis & 1482593 & 79.1 & 20.9 \\
\hline
\end{tabular}

Data expressed as mean $\pm \operatorname{SD}(n=3)$

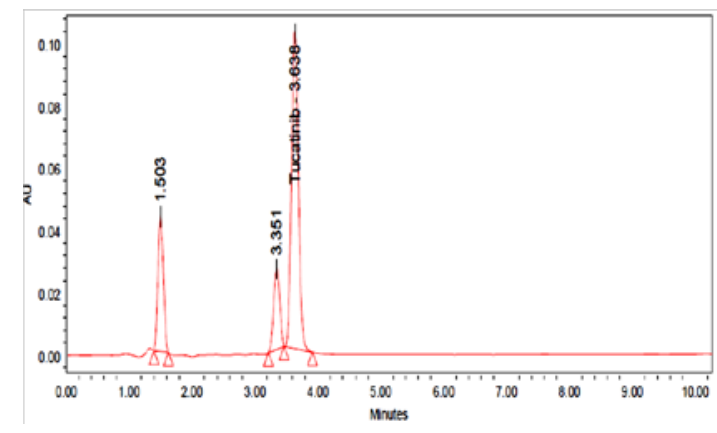

(a)

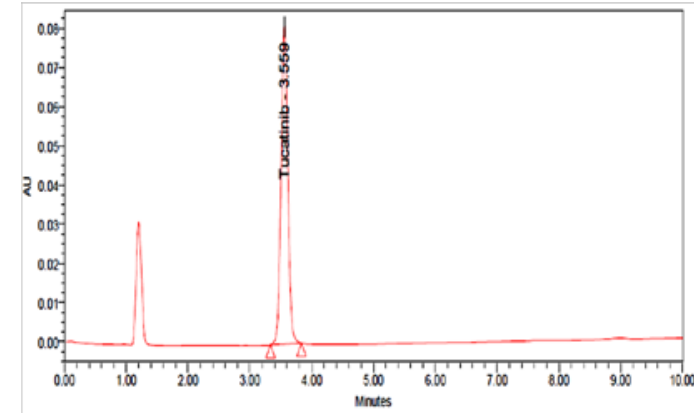

(c)

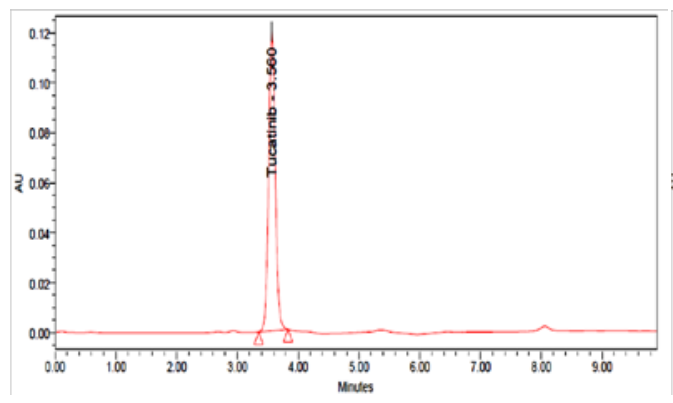

(e)

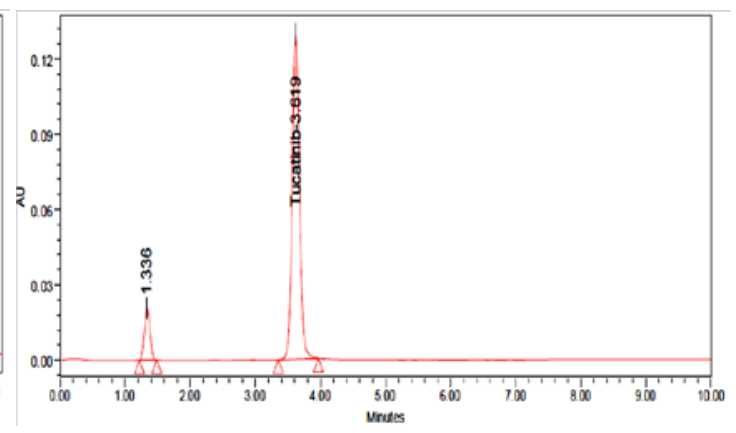

(b)

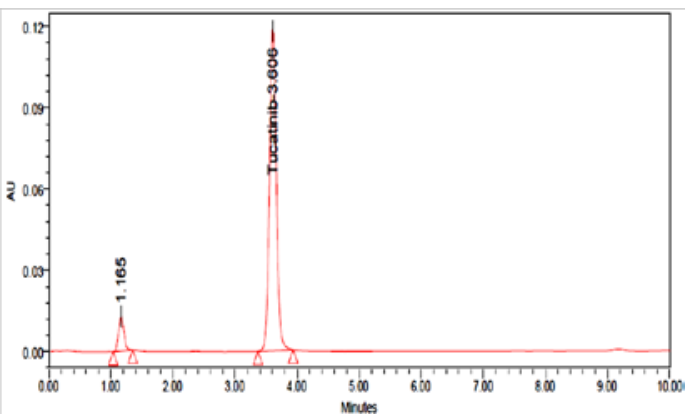

(d)

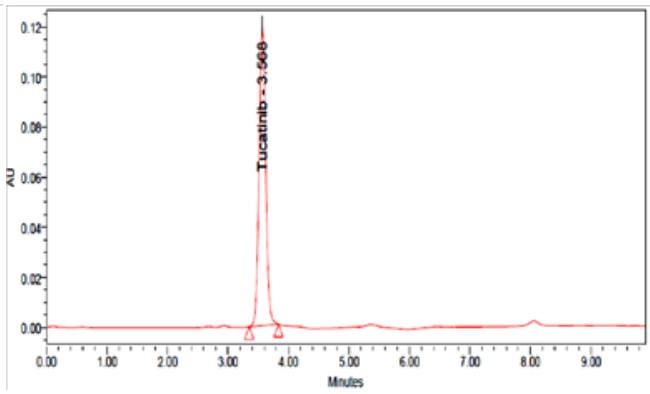

(f)

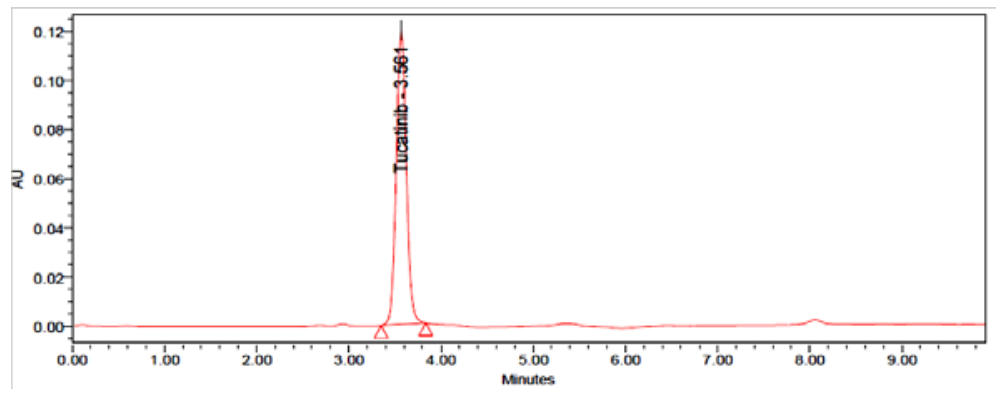

(g)

Fig. 5: Degradation chromatogram of (a) Acidic (b) Alkaline (c) Oxidation (d) Reduction (e) Thermal (f) Photolytic (g) Hydrolysis 


\section{LC-MS/MS studies of forced degradation products}

Four degradation products, DP1, DP2, DP3, and DP4 were identified and characterized by tandem mass spectrometric analysis (LCMS/MS) and accurate mass measurement shown in table 4. DP1 and
DP2 were degraded in acidic conditions, whereas DP3 was degraded in alkaline conditions, DP4 was degraded in reduction condition. The Identification of active drug and its novel degradation product was studied on Agilent Q-TOF of Mass spectrometric (MS) technique with ABSCIEX. Mass measurements of Tucatinib was shown in table 8.

Table 8: Elemental composition and accurate mass measurements of Tucatinib and its degradation products

\begin{tabular}{llllll}
\hline & Molecular formula & Calculate mass & Observed mass & ppm Error & MS/MS fragment ions formed \\
\hline Tucatinib & $\mathrm{C}_{26} \mathrm{H}_{24} \mathrm{~N}_{8} \mathrm{O}_{2}$ & 480.5230 & 480.5232 & 0.4162 & $130,242,347$ \\
DPI & $\mathrm{C}_{20} \mathrm{H}_{21} \mathrm{~N}_{5} \mathrm{O}_{2}$ & 363.0523 & 363.0526 & 0.8263 & $257,145,114$ \\
DPII & $\mathrm{C}_{13} \mathrm{H}_{12} \mathrm{ClN}_{2} \mathrm{O}_{3}$ & 321.0361 & 321.0364 & 0.9344 & 175,148 \\
DPIII & $\mathrm{C}_{13} \mathrm{H}_{10} \mathrm{~N}_{4} \mathrm{O}_{3}$ & 270.0639 & 270.0641 & 0.7405 & 153,119 \\
DP IV & $\mathrm{C}_{21} \mathrm{H}_{17} \mathrm{~N}_{7} \mathrm{O}_{5} \mathrm{~S}$ & 479.0649 & 479.0653 & 0.8349 & $362,241,145$ \\
\hline
\end{tabular}

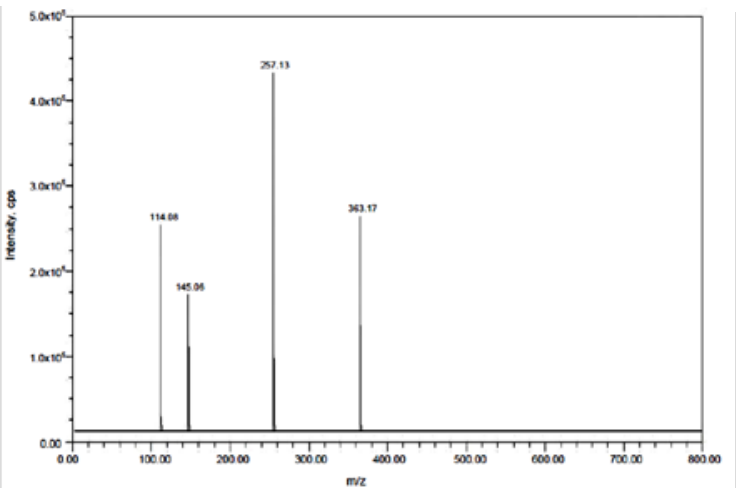

DP1

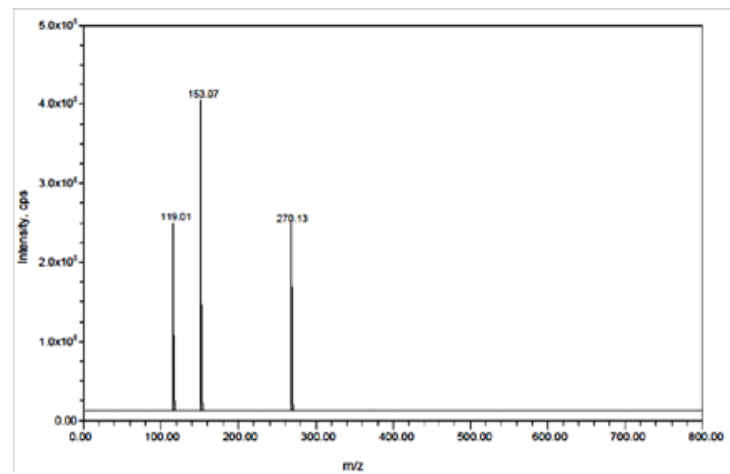

DP3

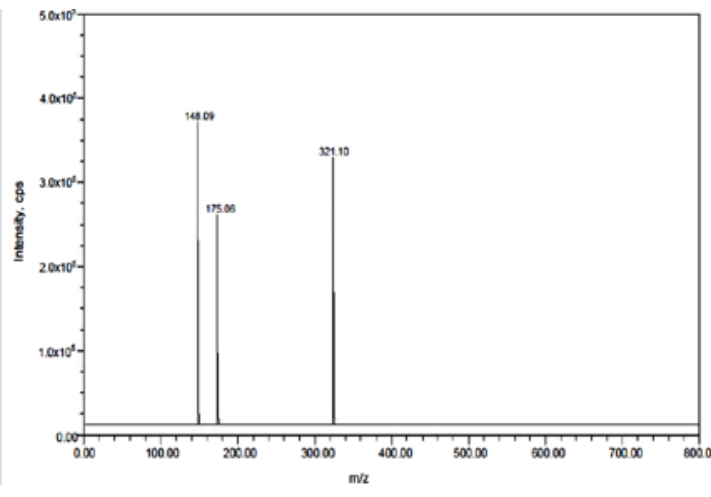

DP2

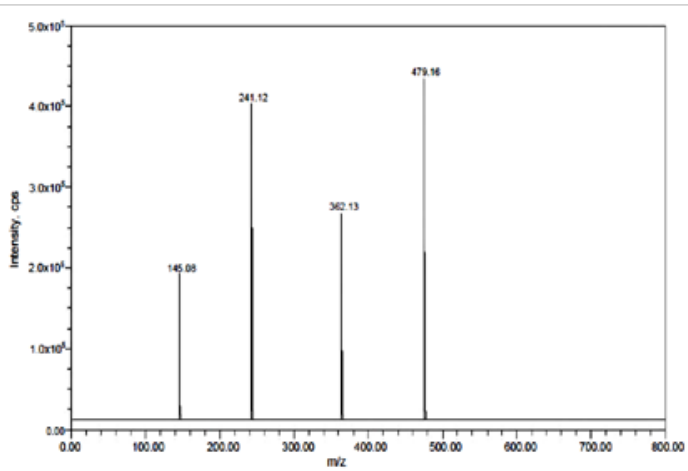

DP4

Fig. 6: ESI-MS-MS spectrum of ions of (A) DP1 (B) DP2 (C) DP3 (D) DP4
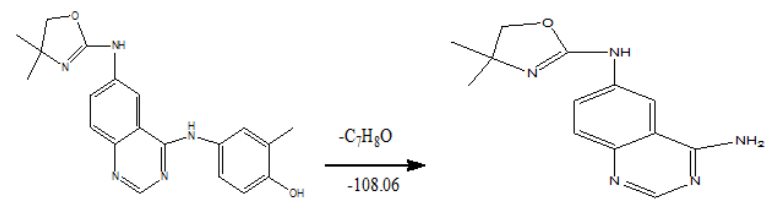

363.17

257.13

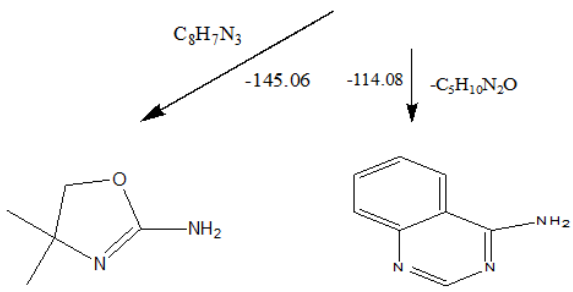

114.08

145.06

Fig. 7: Degradation pathway of DP1 


\section{MS/MS of DP1}

The LC-ESI-MS/MS spectrum of DP1 with $\mathrm{m} / \mathrm{z} 363$ (Rt= $1.503 \mathrm{~min}$ ) was examined in the proposed fragmentation pathway (fig. 7). The degradation ions of $\mathrm{m} / \mathrm{z} 257$ (loss of $\mathrm{C}_{7} \mathrm{H}_{8} \mathrm{O}$ from the parent ion at $\mathrm{m} / \mathrm{z} 363$ ), $\mathrm{m} / \mathrm{z} 145$ (loss of $\mathrm{C}_{5} \mathrm{H}_{10} \mathrm{~N}_{2} \mathrm{O}$ from the parent ion at $\mathrm{m} / \mathrm{z}$ 257), $\mathrm{m} / \mathrm{z} 114$ (loss of $\mathrm{C}_{8} \mathrm{H}_{7} \mathrm{~N}_{3}$ from the parent ion at $\mathrm{m} / \mathrm{z}$ 257) Accordingly, data obtained from MS/MS, elemental composition, and precise mass measurements are shown in (fig. 7).

\section{MS/MS of DP2}

The LC-ESI-MS/MS spectrum of DP2 with m/z 321 (Rt= $3.351 \mathrm{~min}$ ) was examined in the proposed fragmentation pathway (fig. 8). The degradation ions of $\mathrm{m} / \mathrm{z} 175$ (loss of $\mathrm{C}_{5} \mathrm{H}_{9} \mathrm{ClNO} 2$ from the parent ion at $\mathrm{m} / \mathrm{z} 321$ ), $\mathrm{m} / \mathrm{z} 148$ (loss of $\mathrm{C}_{8} \mathrm{H}_{5} \mathrm{~N}_{3} \mathrm{O}_{2}$ from the parent ion at $\mathrm{m} / \mathrm{z}$ 321). Accordingly, data obtained from MS/MS, elemental composition, and precise mass measurements are shown in (fig. 8).

\section{MS/MS of DP3}

The LC-ESI-MS/MS spectrum of DP3 with m/z 270 (Rt= $1.336 \mathrm{~min}$ ) was examined in the proposed fragmentation pathway (fig. 9). The degradation ions of $\mathrm{m} / \mathrm{z} 153$ (loss of $\mathrm{C}_{6} \mathrm{H}_{5} \mathrm{~N}_{3}$ from the parent ion at $\mathrm{m} / \mathrm{z} 270$ ), $\mathrm{m} / \mathrm{z} 119$ (loss of $\mathrm{C}_{7} \mathrm{H}_{7} \mathrm{NO}_{3}$ from the parent ion at $\mathrm{m} / \mathrm{z}$ 270). Accordingly, data obtained from MS/MS, elemental composition, and precise mass measurements are shown in (fig. 9).

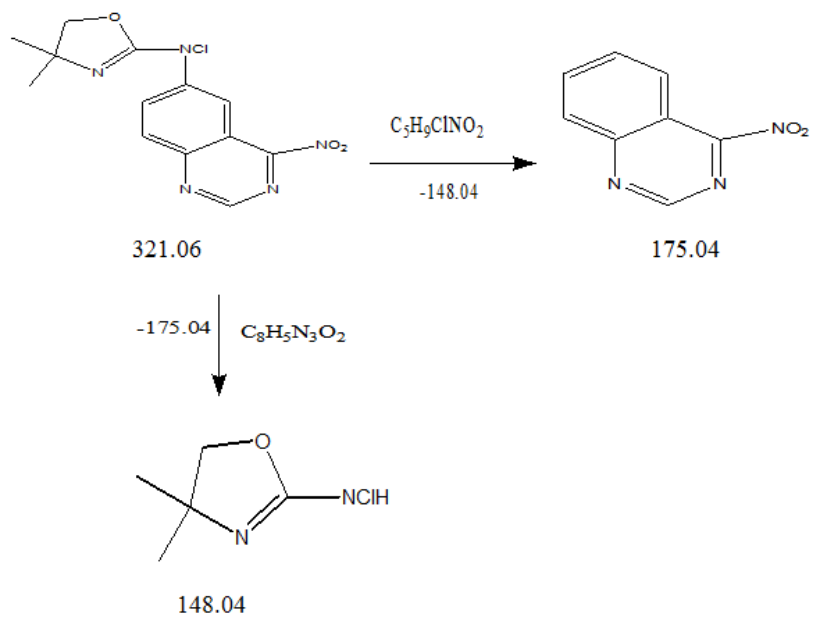

Fig. 8: Degradation pathway of DP2

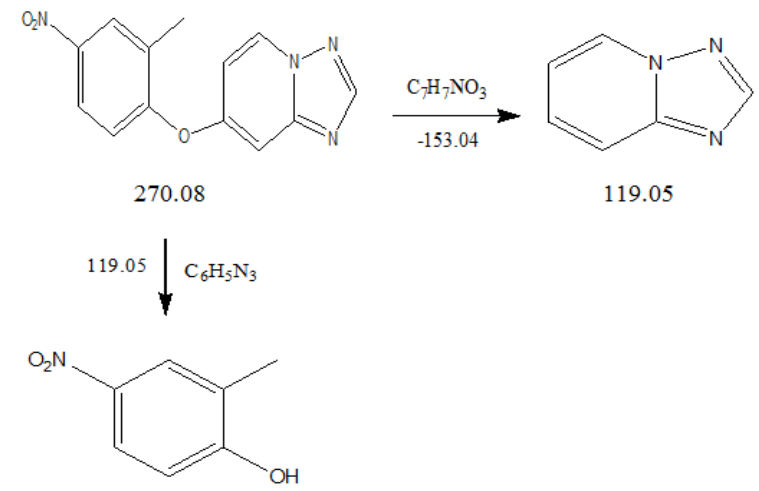

Fig. 9: Degradation pathway of DP3

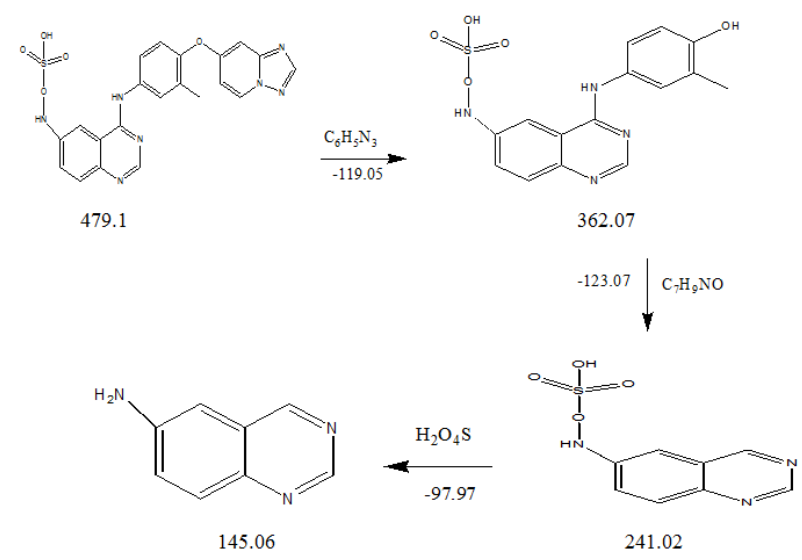

Fig. 10: Degradation pathway of DP4 


\section{MS/MS of DP4}

The LC-ESI-MS/MS spectrum of DP4 with $\mathrm{m} / \mathrm{z} 479$ (Rt= $1.165 \mathrm{~min})$ was examined in the proposed fragmentation pathway (fig. 10). The degradation ions of $\mathrm{m} / \mathrm{z} 362$ (loss of $\mathrm{C}_{6} \mathrm{H}_{5} \mathrm{~N}_{3}$ from the parent ion at $\mathrm{m} / \mathrm{z} 479$ ), $\mathrm{m} / \mathrm{z} 241$ (loss of $\mathrm{C}_{7} \mathrm{H}_{9} \mathrm{NO}$ from the parent ion at $\mathrm{m} / \mathrm{z} 362$ ), $\mathrm{m} / \mathrm{z} 145$ (loss of $\mathrm{H}_{2} \mathrm{O}_{4} \mathrm{~S}$ from the parent ion at $\mathrm{m} / \mathrm{z}$ 241). Accordingly, data obtained from MS/MS, elemental composition, and precise mass measurements are shown in (fig. 10).

\section{CONCLUSION}

The validated stability indicting method developed for the determination of novel kinase inhibitors is specific and selective and more economical. The developed method is compatible for both LC and MS Techniques. Tucatinib degradation was investigated under various stress conditions (hydrolysis, oxidation, photolysis, and thermal). Because the developed method can effectively separate the drug from potential degradants, it can be used to assess the quality of tucatinib in bulk and stability samples. The drug was discovered to be unstable in hydrolytic conditions (basic and acid) and reduction, but stable in oxidation, hydrolysis, photolysis, and thermal stress. Using online LC-ESI-MS-MS experiments combined with precise mass measurements, four previously unknown DPs were identified and characterized. This research could aid in the investigation and characterization of other process-related impurities.

\section{ACKNOWLEDGEMENT}

The authors are grateful to the management of Shree Icon Pharmaceutical Laboratory, Labbipeta, Vijayawada, Andhra Pradesh, India, for providing the necessary facilities and assistance in carrying out this study.

\section{FUNDING}

Nil

\section{AUTHORS CONTRIBUTIONS}

All the authors have contributed equally.

\section{CONFLICTS OF INTERESTS}

\section{Declared none}

\section{REFERENCES}

1. Gross Stefan, Rahal Rami, Stransky Nicolas, Lengauer Christoph, Hoeflich Klaus P. Targeting cancer with kinase inhibitors. J Clin Invest. 2015;125(5):1780-9. doi: 10.1172/JCI76094, PMID 25932675.

2. Jänne Pasi A, Gray Nathanael, Settleman Jeff. Factors underlying sensitivity of cancers to small-molecule kinase inhibitors. Nat Rev Drug Discov. 2009;8(9):709-23. doi: 10.1038/nrd2871, PMID 19629074.

3. Mitri Zahi, Constantine Tina, O'Regan Ruth. The HER2 receptor in breast cancer: pathophysiology, clinical use, and new advances in therapy. Chemother Res Pract. 2012;2012:743193. doi: $10.1155 / 2012 / 743193$.

4. Roy Vivek, Perez Edith A. Beyond trastuzumab: small molecule tyrosine kinase inhibitors in HER-2-positive breast cancer. Oncologist. 2009;14(11):1061-9. doi: 10.1634/ theoncologist.2009-0142, PMID 19887469.

5. Seguin Laetitia, Kato Shumei, Franovic Aleksandra, Camargo M Fernanda, Lesperance Jacqueline, Elliott Kathryn C, Yebra Mayra, Mielgo Ainhoa, Lowy Andrew M, Husain Hatim, Cascone Tina, Diao Lixia, Wang Jing, Wistuba Ignacio I, Heymach John V, Lippman Scott M, Desgrosellier Jay S, Anand Sudarshan, Weis Sara M, Cheresh David A.An integrin $\beta_{3}$-KRAS-RalB complex drives tumour stemness and resistance to EGFR inhibition. Nat Cell Biol. 2014;16(5):457-68. doi: 10.1038/ncb2953, PMID 24747441.

6. Zink Daniele, Fischer Andrew H, Nickerson Jeffrey A. Nuclear structure in cancer cells. Nat Rev Cancer. 2004;4(9):677-87. doi: 10.1038/nrc1430, PMID 15343274.

7. Vlastaridis Panayotis, Papakyriakou Athanasios, Chaliotis Anargyros, Stratikos Efstratios, Oliver Stephen G, Amoutzias Grigorios D. The pivotal role of protein phosphorylation in the control of central yeast metabolism.G3
(Bethesda). 2017;7(4):1239-49. doi: 10.1534/g3.116.037218, PMID 28250014.

8. Sharma Saumya, Guthrie Patrick H, Chan Suzanne S, Haq Syed, Taegtmeyer Heinrich. Glucose phosphorylation is required for insulin-dependent mTOR signalling in the heart. Cardiovasc Res. 2007;76(1):71-80. doi: 10.1016/j.cardiores.2007.05.004, PMID 17553476.

9. Yu Jiabo, Sun Xiang, Goie Jian Yi Gerald, Zhang Yongliang. Regulation of host immune responses against influenza virus infection by mitogen-activated protein kinases (MAPKs). Microorganisms. 2020;8(7):1067. 10.3390/microorganisms8071067, PMID 32709018.

10. Cargnello Marie, Roux Philippe P. Activation and function of the MAPKs and their substrates, the MAPK-activated protein kinases. Microbiol Mol Biol Rev. 2011;75(1):50-83. doi: 10.1128/MMBR.00031-10, PMID 21372320.

11. Hill Michelle M, Hemmings Brian A. Inhibition of protein kinase B/Akt. Implications for cancer therapy. Pharmacol Ther. 2002;93(2-3):243-51. doi: 10.1016/s01637258(02)00193-6, PMID 12191616.

12. Xie Jiuyong, Weiskirchen Ralf. What Does the "AKT" stand for in the name "AKT Kinase"? some historical comments. Front Oncol. 2020;10:1329. doi: 10.3389/fonc.2020.01329, PMID 32850422 .

13. Lademann Juergen, Martschick Anja, Kluschke Franziska, Richter Heike, Fluhr Joachim W, Patzelt Alexa, Jung Sora, Chekerov Radoslav, Darvin Maxim E, Haas Norbert, Sterry Wolfram, Zastrow Leonhard, Sehouli Jalid. Efficient prevention strategy against the development of a palmar-plantar erythrodysesthesia during chemotherapy. Skin Pharmacol Physiol. 2014;27(2):6670. doi: 10.1159/000351801, PMID 23969763.

14. Rosenbeck Lindsay, Kiel Patrick J. Images in clinical medicine. Palmar-plantar rash with cytarabine therapy. N Engl J Med.2011;364(3):e5. doi: 10.1056/NEJMicm1006530, PMID 21247311.

15. Manov Irena, Motanis Helen, Frumin Idan, Iancu Theodore C. Hepatotoxicity of anti-inflammatory and analgesic drugs: ultrastructural aspects. Acta Pharmacol Sin. 2006;27(3):25972. doi: 10.1111/j.1745-7254.2006.00278.x, PMID 16490160.

16. Brocklehurst Paul, Tickle Martin, Glenny Anne Marie, Lewis Michael A, Pemberton Michael N, Taylor Jennifer, Walsh Tanya, Riley Philip, Yates Julian M. Systemic interventions for recurrent aphthous stomatitis (mouth ulcers). Cochrane Database Syst Rev. 2012;9(9):CD005411. doi: 10.1002/14651858.CD005411.pub2, PMID 22972085.

17. Lawton CL. Obesity: a disorder of appetite. Pract Diab Int. 1993;10(1):10-2. http://doi:10.1002/pdi.1960100105, doi: $10.1002 /$ pdi.1960100105.

18. Viniol Annika, Keunecke Christian, Biroga Tobias, Stadje Rebekka, Dornieden Katharina, Bösner Stefan, Donner Banzhoff Norbert, Haasenritter Jorg, Becker Annette. Studies of the symptom abdominal pain- a systematic review and metaanalysis. Fam Pract. 2014;31(5):517-29. doi: 10.1093/fampra/cmu036, PMID 24987023.

19. Potturi Ramadevi, Kantipudi Rambabu. Bio analytical method development and validation for Ezetimibe and Pitavastain and its applications to pharmacokinetic studies in Rabbit plasma by using LCMS/MS. IJRPS 2020;11(4):7854-62. doi: 10.26452/ijrps.v11i4.4670.

20. Eluru Asha. Surendra Babu K. Bio analytical method development and validation for Aplidine in rat plasma and their pharmacokinetic studies by LCMS. World J Pharm Pharm Sci. 2019;8:1201-9.

21. Ramchandran D, Kethipalli Anita, Krishnamurthy Mannam. Bioanalytical method development and validation of daunorubicin and cytrarabine in rat plasma by LC-MS/MS and its application in pharmacokinetic studies. J Pharm Sci Res. 2020;12:381-6.

22. Shalini K, Ilango K. Development, evaluation and RP-HPLC method for simultaneous estimation of quercetin, ellagic acid and kaempferol in a polyherbal formulation. Int J Appl Pharm. 2021;13:183-92.

23. Malak Y, Al-Bathish AA, gazy MK, El-Jamal. Rp-hplc and chemometric methods for the determination of two anti- 
diabetic mixtures; metformin hydrochloride-canagliflozin and metformin hydrochloride-gliclazide in their pharmaceutical formulation. Int J Pharm Pharm Sci. 2020;12:83-94.

24. Girija KS, Kasimala BB, Anna VR. A new high-performance liquid chromatography method for the separation and simultaneous quantification of eptifibatide and its impurities in pharmaceutical injection formulation. Int J Appl Pharm. 2021;13:165-72. doi: 10.22159/ijap.2021v13i2.39895.

25. Balaji Gupta VLN T, Venkateswara Rao B, Kishore Babu B. RPHPLC (stability-indicating) based assay method for the simultaneous estimation of doravirine, tenofovir disoproxil fumarate and lamivudine. Int J Appl Pharm. 2021;13:153-9.

26. International conference on harmonization. ICH harmonized tripartite guideline. Validation of analytical procedures: text and methodology. Vol. Q2(R1); 2005.

27. Manoranjani M. A study of method development, validation and forced degradation for simultaneous quantification of cisplatin and fluorouracil in bulk and pharmaceutical dosage form by RP-HPLC. J Pharm Sci Res. 2021;13:155-61.

28. Hemanth Kumar AK, Sudha V, Vijayakumar A, Padmapriyadarsini C. Simultaneous method for the estimation of bidaquiline and delamanid in human plasma using high- performance liquid chromatography. Int J Pharm Pharm Sci. 2021;13:36-40.

29. Shanmugasundaram P, Kamarapu SK. RP-HPLC method for the simultaneous estimation and validation of amlodipine besylate and atenolol in bulk and tablet dosage form in biorelevant dissolution medium (Fassif). Res J Pharm Technol. 2017;10(10):3379-85. doi: 10.5958/0974-360X.2017.00601.1.

30. Sruthi A, Uttam Prasad P. Stability indicating method development and validation of fimasartan by reverse-phase high-performance liquid chromatography in bulk and pharmaceutical dosage form. Asian J Pharm Clin Res. 2021;14:138-46.

31. Lakka Narasimha S, Kuppan Chandrasekar, Srinivas Kona S, Yarra Raviteja. Separation and characterization of new forced degradation products of dasatinib in tablet dosage formulation using LC-MS and stability-indicating HPLC methods. Chromatographia. 2020;83(8):947-62. doi: 10.1007/s10337020-03920-0.

32. Chavan Balasaheb B, Vijaya Jyothi P, Kalariya PD, Srinivas R, Talluri MVNK, Pradipbhai D Kalariya. Alcaftadine: selective separation and characterization of degradation products by LCQTOF-MS/MS. Chromatographia. 2018;81(4):631-8. doi: 10.1007/s10337-018-3489-1. 